\title{
EUV damage threshold measurements of Mo/Si multilayer mirrors
}

\author{
Matthias Müller • Frank Barkusky • Torsten Feigl • \\ Klaus Mann
}

Received: 12 June 2012 / Accepted: 26 June 2012 / Published online: 10 July 2012

(c) The Author(s) 2012. This article is published with open access at Springerlink.com

\begin{abstract}
We present 1-on-1 and 10-on-1 damage threshold investigations on $\mathrm{Mo} / \mathrm{Si}$ multilayers with EUV radiation of $13.5 \mathrm{~nm}$ wavelength, using a table-top laser produced plasma source based on solid gold as target material. The experiments were performed on different types of Mo/Si mirror, showing no significant difference in single pulse damage thresholds. However, the damage threshold for ten pulses is $\approx 60 \%$ lower than the single pulse threshold, implying a defect dominated damage process. Using Nomarski (DIC) and atomic force microscopy (AFM) we analysed the damage morphologies, indicating a primarily thermally induced damage mechanism. Additionally, we studied the radiationinduced change of reflectivity upon damage of a multilayer mirror.
\end{abstract}

\section{Introduction}

Damage studies on optical materials for IR, VIS and UV lasers are performed since many decades now, and the underlying material interaction mechanisms have been studied extensively [1]. Currently, more and more powerful EUV

\footnotetext{
M. Müller $(\bowtie) \cdot$ K. Mann

Laser-Laboratorium-Göttingen e.V., Hans-Adolf-Krebs-Weg 1,

37077 Göttingen, Germany

e-mail: matthias.mueller@1lg-ev.de

Fax: +49-0-551503599

F. Barkusky

KLA Tencor Corporation, 1 Technology Drive, Milpitas, CA

95035, USA

Present address:

T. Feigl

Fraunhofer-Institut für Angewandte Optik und Feinmechanik IOF,

Albert-Einstein-Straße 7, 07745 Jena, Germany
}

sources for next generation semiconductor microlithography are being developed, for which novel optical elements like multilayer or grazing-incidence mirrors are required. Consisting of very thin alternating layers, especially molybdenum and silicon for the wavelength of $13.5 \mathrm{~nm}$, multilayer mirrors are employed for normal reflection angles. These mirrors are presently being optimized with respect to thermal resistivity and reflectivity [2, 3]. However, only very few ablation [4-6] and damage threshold studies at a wavelength of $13.5 \mathrm{~nm}$ are available up to now for these optical elements [7, 8]. Barkusky et al. [9] investigated EUV induced single pulse damage thresholds of grazing-incidence mirrors, Mo/Si multilayer mirrors and mirror substrate materials as fused silica, silicon and $\mathrm{CaF}_{2}$, presenting first damage threshold data for nanosecond pulse durations.

In this paper we present further investigations of EUV induced damage thresholds of three different $\mathrm{Mo} / \mathrm{Si}$ multilayer mirrors. We examined single and ten pulse damage thresholds and corresponding radiation-induced surface morphologies. Furthermore, we studied the change of reflectivity caused by radiation-induced damage of the mirror by spatially resolved observation of the reflected EUV radiation.

\section{Experimental setup}

The experimental setup used for the measurements was described already previously [9]. It includes a laser-based EUV source and a separated optics chamber connected to this source (cf. Fig. 1) [10-12]. EUV radiation is generated by focusing a Nd:YAG laser (Innolas, wavelength $1064 \mathrm{~nm}$, pulse energy $700 \mathrm{~mJ}$, pulse duration $8.8 \mathrm{~ns}$ ) onto a rotating solid Au target, yielding a plasma diameter of about $50 \mu \mathrm{m}$ (FWHM) [9]. The plasma is generated in the center of a 
Fig. 1 Schematics of EUV source and optics system (left) and photo of the setup (right)

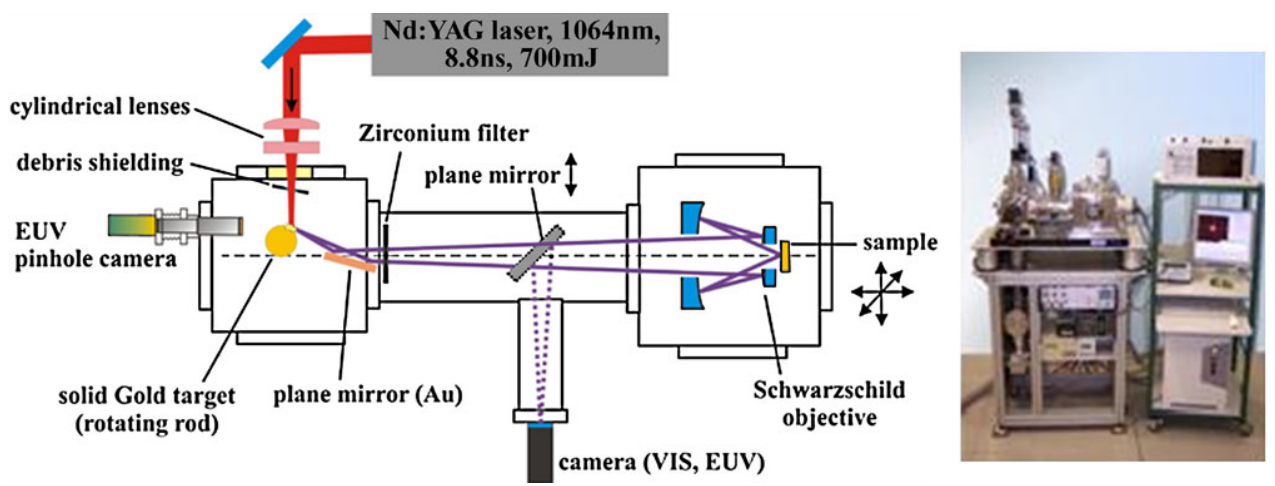

Table 1 Output parameters of the laser-based EUV plasma source

\begin{tabular}{ll}
\hline Wavelength $(\lambda)$ & $13.5 \mathrm{~nm}$ \\
Pulse duration $(\tau)$ & $\approx 8.8 \mathrm{~ns}(\mathrm{FWHM})$ \\
Repetition rate & $1 \mathrm{~Hz}$ \\
Spectral filtering & $2 \times \mathrm{Mo} / \mathrm{Si}$ reflections \\
EUV spot size & $2.65 \mu \mathrm{m} \times 5.45 \mu \mathrm{m}(\mathrm{FWHM})$ \\
(focus of objective) & \\
EUV energy density & $\leq 3.6 \mathrm{~J} / \mathrm{cm}^{2}$ (without zirconium filter) \\
\hline
\end{tabular}

vacuum chamber, which is evacuated below $10^{-4}$ mbar due to the low mean free path of EUV radiation at atmospheric pressure.

An EUV Schwarzschild objective consisting of two spherical, annular mirror substrates coated with $\mathrm{Mo} / \mathrm{Si}$ multilayers (reflectivity $R \approx 0.65 @ 13.5 \mathrm{~nm}$ ) provides high EUV fluences [13]. The incidence angles on the sample range from $12.7^{\circ}$ to $26.6^{\circ}$ (mean angle $\approx 20^{\circ}$ ) according to the numerical aperture of the Schwarzschild objective [9]. Selected properties of the EUV source and the optics system as used in the experiments are compiled in Table 1.

1-on-1 damage tests were performed with the described setup at $13.5 \mathrm{~nm}$ according to ISO 11254 [14], irradiating 10 positions with single EUV pulses at constant fluence. The number of damaged positions divided by the total number of irradiated sites results in the damage probability, which was determined for several EUV energy densities [14]. The onset of damage and its morphology were detected using Nomarski (DIC) and atomic force microscopy. Damage is considered as permanent change in the surface morphology as a result of interaction with the incident EUV radiation.

Due to mechanical instabilities of the rotating solid $\mathrm{Au}$ target (cf. Fig. 1) the positional stability of the EUV plasma and thus the maximum number of overlapping pulses are limited. To guarantee a proper measurement of multiple pulse damage thresholds a maximum number of ten pulses per site were applied.

The EUV plasma reflected from the mirror samples can be observed with an EUV sensitive camera by inserting a plane $\mathrm{Mo} / \mathrm{Si}$ mirror $\left(45^{\circ} @ 13.5 \mathrm{~nm}\right)$ partly in the beam path.

\section{Experimental results}

The measurements below were conducted with 3 different $\mathrm{Mo} / \mathrm{Si}$ multilayer mirrors designed for a maximum reflectivity at $16^{\circ}$ incidence angle @ $13.5 \mathrm{~nm}$. One mirror consists of $\mathrm{Mo} / \mathrm{Si}$ multilayers only, the second has a ruthenium capping layer ([Mo/Si $] \mathrm{Ru})$, and the third intra-diffusion barriers $(\mathrm{Mo} / \mathrm{C} / \mathrm{Si} / \mathrm{C})$ with a barrier thickness of $0.6 \mathrm{~nm}$. The mirrors are made of 60 bilayers of Mo and Si with a periodicity of $6.90 \mathrm{~nm}$ and Mo layer thickness of $2.42 \mathrm{~nm}$.

\subsection{Single pulse damage thresholds}

Results of the damage tests calculated according to Ref. [14] are displayed in Fig. 2, showing single pulse thresholds of about $(0.09 \pm 0.06) \mathrm{J} / \mathrm{cm}^{2}$ for $[\mathrm{Mo} / \mathrm{Si}] \mathrm{Ru},(0.20 \pm 0.06) \mathrm{J} / \mathrm{cm}^{2}$ for $\mathrm{Mo} / \mathrm{Si}$ and $(0.26 \pm 0.04) \mathrm{J} / \mathrm{cm}^{2}$ for $\mathrm{Mo} / \mathrm{C} / \mathrm{Si} / \mathrm{C}$, respectively. Energy density and damage probability are determined with a relative uncertainty of $10 \%$. The error in the energy density stems from the uncertainty in EUV pulse energy measurement and the determination of the focal size. Since the 1-on-1 damage test was performed twice for the $\mathrm{Mo} / \mathrm{C} / \mathrm{Si} / \mathrm{C}$ mirror the resulting damage probabilities were averaged, leading to a statistical error for the damage probability of this sample. The absolute error results from the uncertainty of the parameters of the linear regression.

The damage threshold measured for the $\mathrm{Mo} / \mathrm{Si}$ mirror is about four times lower than that determined by Barkusky et al. for a similar mirror [9]. However, the latter was designed for a maximum reflectivity at an incidence angle of $20^{\circ}$, corresponding to the mean incidence angle on the sample given by the Schwarzschild optics. Thus, the mirror designed for $16^{\circ}$ used in this experiment absorbs a larger fraction of the EUV radiation compared to the sample used in reference [9], giving rise to a lower damage threshold. Furthermore, there could be an effect of out-of-band radiation reducing the threshold since this damage test was performed without a zirconium filter. On the other hand, the damage threshold obtained with EUV femtosecond pulses at FLASH (Free electron laser Hamburg) [7] is still lower than that determined in this experiment. 
Figure 3 shows Nomarski (DIC) images of damaged sites of the $\mathrm{Mo} / \mathrm{Si}$ and $\mathrm{Mo} / \mathrm{C} / \mathrm{Si} / \mathrm{C}$ mirror, as well as corresponding AFM micrographs for selected energy densities between 0.6 and $2.0 \mathrm{~J} / \mathrm{cm}^{2}$.

For fluences just above the damage threshold small craters with a maximum depth of $60 \mathrm{~nm}$ occur, merging into one single crater at $\approx 0.9 \mathrm{~J} / \mathrm{cm}^{2}$. Due to the random distribution of the small pits (cf. Fig. 3 top row) this effect may be affiliated to sites with higher absorption such as defects or inhomogeneities in the multilayer structure. This supports previous results of experiments with this setup [15], of experiments performed with EUV femtosecond pulses at

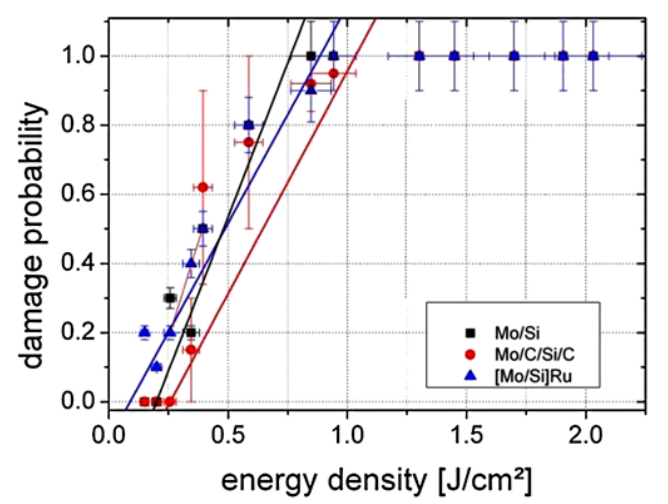

Fig. 2 Damage probability (1-on-1) plot of different Mo/Si multilayer mirrors $\left(16^{\circ} @ 13.5 \mathrm{~nm}\right)$ on silicon substrates
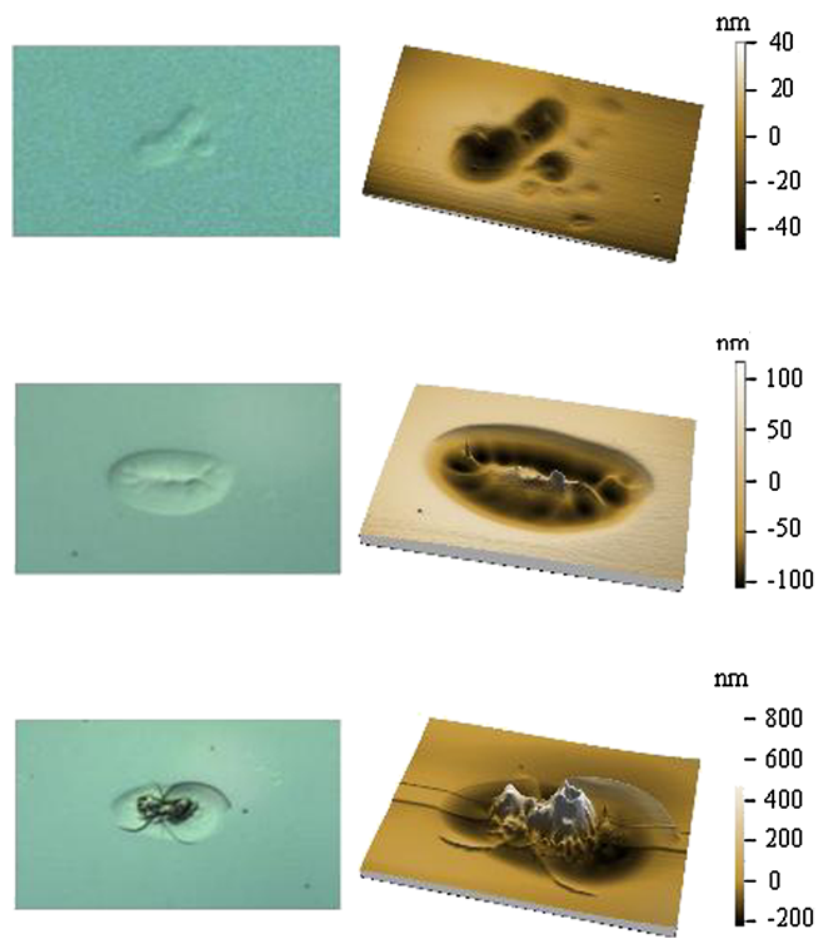

$\mathrm{nm}$
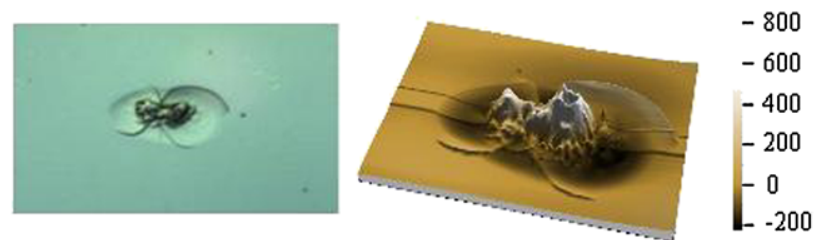
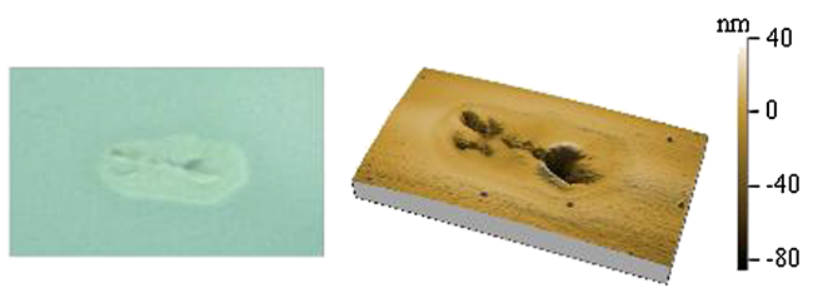

FLASH [7, 16] and at higher wavelengths [17-21], where very similar structures were observed.

For higher fluences the surface morphology of the damaged Mo/Si mirror is visually similar to the gold mirrors investigated in Ref. [15]. In particular a bump is formed in the middle of the crater, indicating a damage mechanism primarily driven by thermal heating of the multilayer structure. Furthermore, compaction of the multilayer mirror upon silicide formation might play a role in the damaging process [7].

In contrast to a primarily thermally driven damage mechanism a non-thermally driven damage profile is absolutely smooth, e.g. as shown for fused silica in Ref. [9], where the damage is probably due to a photon-induced direct bondbreaking process.

Whereas the $[\mathrm{Mo} / \mathrm{Si}] \mathrm{Ru}$ mirror exhibits similar damage morphologies as the Mo/Si sample, the $\mathrm{Mo} / \mathrm{C} / \mathrm{Si} / \mathrm{C}$ mirror shows a slightly different behavior: The bump in the center of the crater does not occur until high energy densities are reached. This effect may be based on differences in thermal diffusivity or the formation of compounds ( $\mathrm{SiC}$ ) with a different density due to the intra-diffusion barriers of the $\mathrm{Mo} / \mathrm{C} / \mathrm{Si} / \mathrm{C}$ mirror.

\subsection{Multiple pulse damage effects}

In order to investigate multiple pulse damage effects, 1on- 1 and 10-on-1 damage tests were performed with the
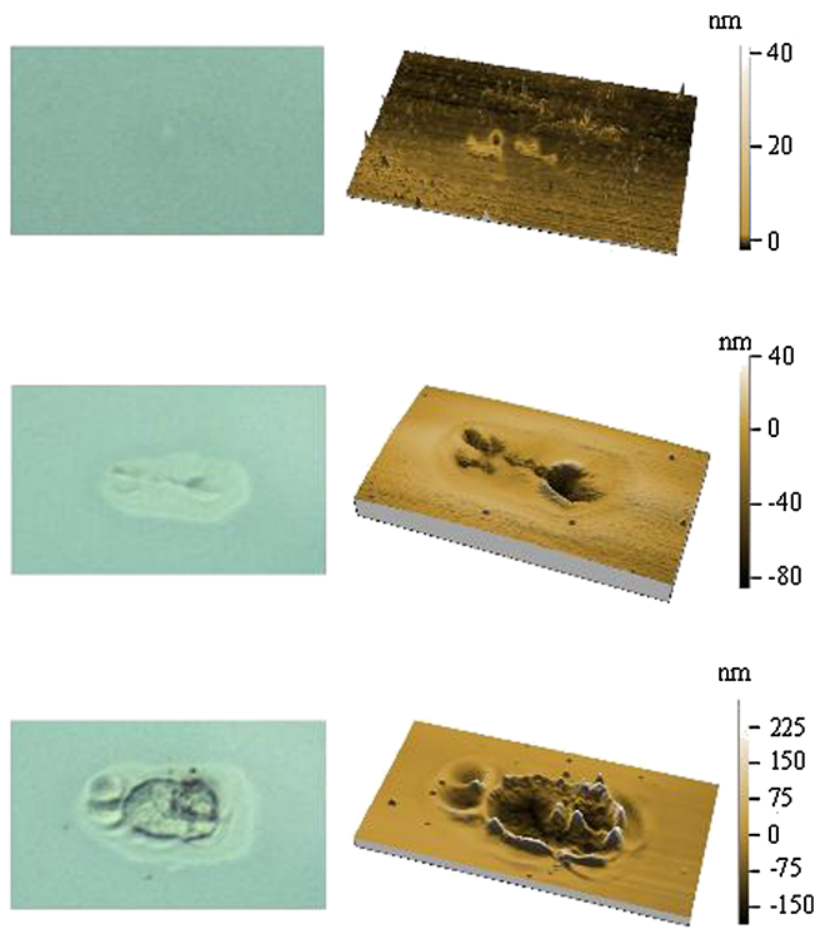

Fig. 3 Nomarski (DIC) images (image size $25 \mu \mathrm{m} \times 15 \mu \mathrm{m})$ of the $\mathrm{Mo} / \mathrm{Si}($ left $)$ and the $\mathrm{Mo} / \mathrm{C} / \mathrm{Si} / \mathrm{C}$ (right) mirror $\left(16^{\circ} @ 13.5 \mathrm{~nm}\right)$ for selected energy densities $\left(0.6,1.3\right.$ and $2.0 \mathrm{~J} / \mathrm{cm}^{2}$ from top to bottom) and corresponding AFM micrographs (image size $20 \mu \mathrm{m} \times 10 \mu \mathrm{m}$ ) 
$\mathrm{Mo} / \mathrm{C} / \mathrm{Si} / \mathrm{C}$ mirror, irradiating six positions with single EUV pulses and six positions with 10 EUV pulses at constant fluence. Again the damage probability was determined for different EUV energy densities according Ref. [14]. The results are shown in Fig. 4, displaying a single pulse damage threshold of about $(0.26 \pm 0.04) \mathrm{J} / \mathrm{cm}^{2}$ and a ten pulse damage threshold of about $(0.10 \pm 0.05) \mathrm{J} / \mathrm{cm}^{2}$. Accordingly, the 10-on- 1 threshold is $\approx 60 \%$ lower than the single pulse threshold. Since there is a certain probability $(<1)$ that a specific defect will lead to damage in a single pulse, the occurrence of damage is more likely when multiple pulses are applied. Thus, the ten pulse damage is more deterministic, being recognizable in the steeper slope of the corresponding damage probability compared to single pulses.

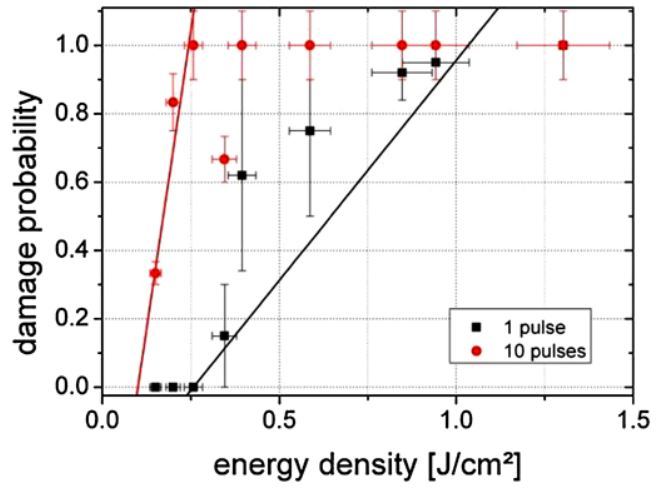

Fig. 4 1-on-1 and 10-on-1 damage probability plot of a $\mathrm{Mo} / \mathrm{C} / \mathrm{Si} / \mathrm{C}$ mirror $\left(16^{\circ} @ 13.5 \mathrm{~nm}\right)$
The effect of phase-transitions, crystallization or $\mathrm{SiC}$ formation on the damage threshold was not investigated in the experiments but could additionally influence the damaging process.

\subsection{Change of reflectivity}

The reflectivity change associated with the damaging process was monitored in order to investigate the possibility to establish an online damage detection tool. For this purpose, the EUV radiation reflected from the $\mathrm{Mo} / \mathrm{C} / \mathrm{Si} / \mathrm{C}$ sample was acquired at low fluence with the EUV camera (cf. Fig. 1), both before and after the damaging pulse (cf. Fig. 5). Damage of the mirror was obtained by irradiating it with five pulses (without plane mirror in the beam path). Figure 5 also displays the corresponding Nomarski (DIC) images of the damaged sites for selected energy densities. The reflected EUV intensity obviously decreases with increasing energy density due to an enlarged damaged area of the mirror.

The relative reflectivity was determined by dividing the maximum sums of the averaged pixel counts in a constant area $(130 \mu \mathrm{m} \times 80 \mu \mathrm{m})$ of the profiles before and after the damaging pulses. Figure 6 displays the relative reflectivity, showing no significant change for low energy densities $\left(<0.9 \mathrm{~J} / \mathrm{cm}^{2}\right)$. Above this fluence the reflectivity decreases, reaching a constant value of nearly 0.4 for about $2.0 \mathrm{~J} / \mathrm{cm}^{2}$.

Obviously, although the sample is seriously damaged (cf. Fig. 4), part of the EUV radiation is still reflected by the intact edges of the irradiated site. Furthermore, it is possible that the multilayer structure stays partly intact as seen for
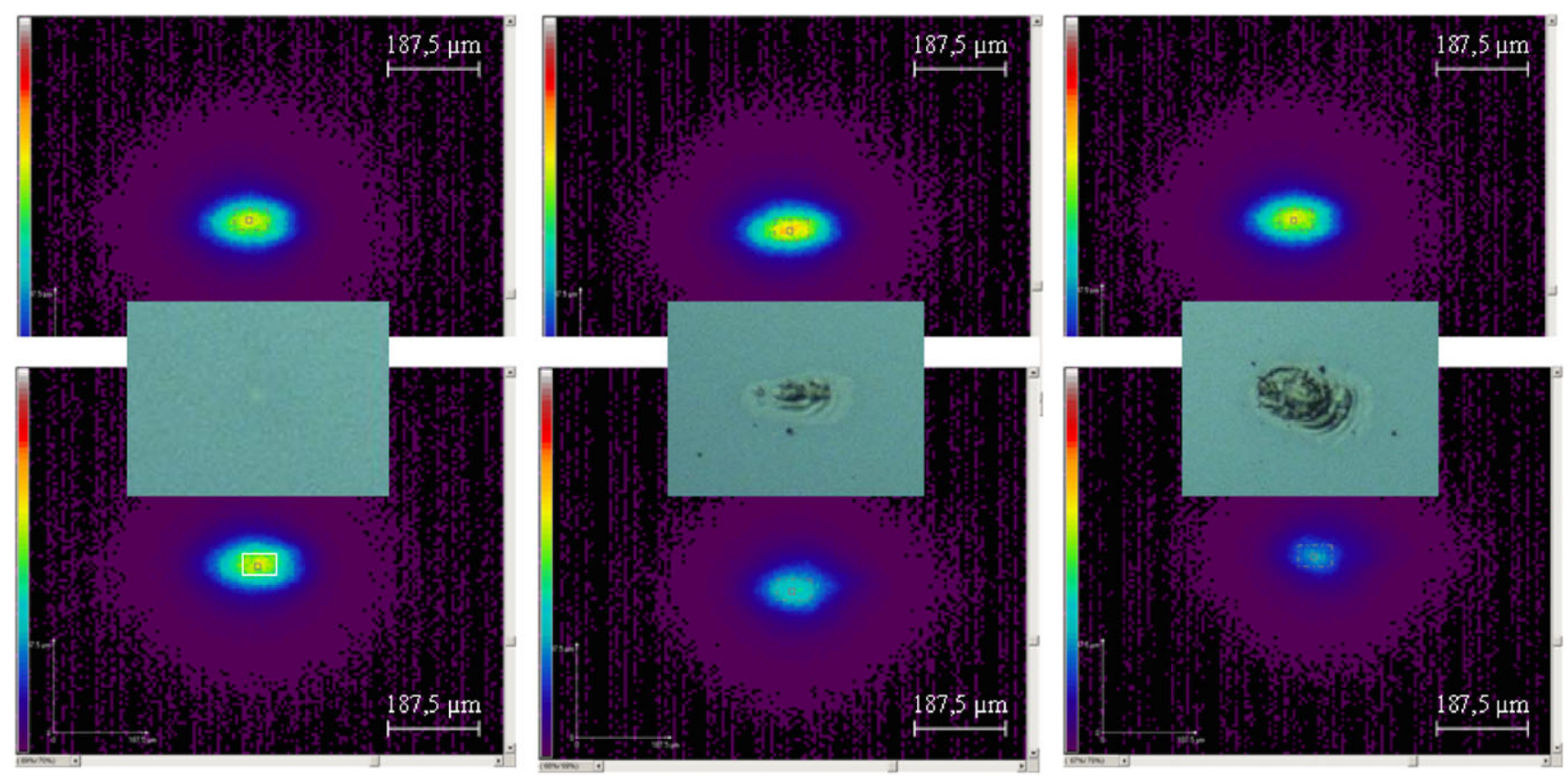

Fig. 5 Nomarski (DIC) images (middle row, image size $20 \mu \mathrm{m} \times 15 \mu \mathrm{m}$ ) of a Mo/C/Si/C mirror (16 $@ 13.5 \mathrm{~nm})$ for $0.25,1.4 \mathrm{and} 2.0 \mathrm{~J} / \mathrm{cm}^{2}$ together with before (top row) and after images (bottom row) of the reflected EUV radiation 


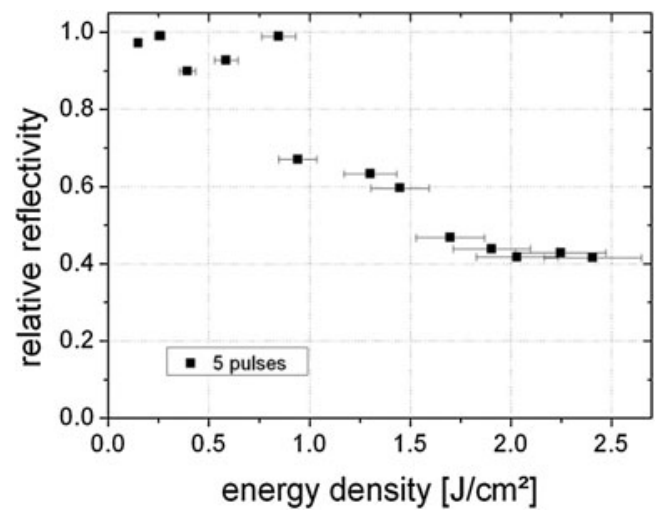

Fig. 6 Relative reflectivity of the $\mathrm{Mo} / \mathrm{C} / \mathrm{Si} / \mathrm{C}$ mirror $\left(16^{\circ} @ 13.5 \mathrm{~nm}\right)$ as a function of the fluence of five damaging pulses

femtosecond damage experiments at FLASH [7] and part of the EUV radiation is reflected by these intact multilayers. However, the loss of reflectivity determined in this measurement cannot be detected until the small defect induced damaged spots (cf. Fig. 3, top right) merge to a single large crater. Thus, the online damage detection is only possible for energy densities being highly above the damage threshold.

\section{Conclusion}

In this paper we have presented EUV single and ten pulse damage threshold investigations on three different $\mathrm{Mo} / \mathrm{Si}$ multilayer mirrors using a nanosecond table-top EUV source. The 1-on-1 damage thresholds do not significantly differ between the three samples, although one mirror is capped with a ruthenium layer and another has intra-diffusion barriers. However, the diverse material properties of the samples lead to slightly different damage morphologies for the $\mathrm{Mo} / \mathrm{C} / \mathrm{Si} / \mathrm{C}$ mirror compared to the $\mathrm{Mo} / \mathrm{Si}$ and $[\mathrm{Mo} / \mathrm{Si}] \mathrm{Ru}$ mirrors, being probably due to differences in thermal diffusivity or the formation of compounds ( $\mathrm{SiC})$ with a different density.

Furthermore, the damage experiment performed with the $\mathrm{Mo} / \mathrm{C} / \mathrm{Si} / \mathrm{C}$ mirror shows a 10 -on-1 pulse damage threshold being $\approx 60 \%$ lower than the single pulse threshold. This result is compatible with a defect induced damage mechanism, substantiated by AFM images of the mirror surface for low energy densities (cf. Fig. 3, top right).

Acquiring the reflected EUV radiation before and after damaging pulses we obtained the relative reflectivity of the $\mathrm{Mo} / \mathrm{C} / \mathrm{Si} / \mathrm{C}$ mirror. A significant change of reflectivity can only be observed for fluences $>0.9 \mathrm{~J} / \mathrm{cm}^{2}$ leading to a single crater damage. Since part of the EUV radiation is still reflected from intact edges of the severely damaged sites or by partly intact multilayers, the relative reflectivity reaches a constant value of about 0.4 at energy densities $>2.0 \mathrm{~J} / \mathrm{cm}^{2}$.
Acknowledgement The financial support by the "Deutsche Forschungsgemeinschaft" within the Sonderforschungsbereich 755 "Nanoscale Photonic Imaging" is gratefully acknowledged.

Open Access This article is distributed under the terms of the Creative Commons Attribution License which permits any use, distribution, and reproduction in any medium, provided the original author(s) and the source are credited.

\section{References}

1. Proceedings of SPIE, Boulder Damage Symposium (1996-2011)

2. T. Feigl, S. Yulin, N. Benoit, N. Kaiser, Microelectron. Eng. 83, 703-706 (2006)

3. H. Takenaka, T. Kawamura, J. Electron Spectrosc. Relat. Phenom. 80, 381 (1996)

4. T. Makimura, Y. Kenmotsu, H. Miyamoto, H. Niino, K. Murakami, Surf. Sci. 593(1-3), 248-251 (2005)

5. L. Juha et al., Appl. Phys. Lett. 86, 034109 (2005)

6. A. Bartnik, H. Fiedorowicz, R. Jarocki, L. Juha, J. Kostecki, R. Rakowski, M. Szczurek, Appl. Phys. B 82(4), 529-532 (2006)

7. A.R. Khorsand, R. Sobierajski, E. Louis, S. Bruijn, E.D. van Hattum, R.W.E. van de Kruijs, M. Jurek, D. Klinger, J.B. Pelka, L. Juha, T. Burian, J. Chalupsky, J. Cihelka, V. Hajkova, L. Vysin, U. Jastrow, N. Stojanovic, S. Toleikis, H. Wabnitz, K. Tiedtke, K. Sokolowski-Tinten, U. Shymanovich, J. Krzywinski, S. HauRiege, R. London, A. Gleeson, E.M. Gullikson, F. Bijkerk, Opt. Express 18, 700-712 (2010)

8. R. Sobierajski, S. Bruijn, A.R. Khorsand, E. Louis, R.W.E. van de Kruijs, T. Burian, J. Chalupsky, J. Cihelka, A. Gleeson, J. Grzonka, E.M. Gullikson, V. Hajkova, S. Hau-Riege, L. Juha, M. Jurek, D. Klinger, J. Krzywinski, R. London, J.B. Pelka, T. Płociński, M. Rasiński, K. Tiedtke, S. Toleikis, L. Vysin, H. Wabnitz, F. Bijkerk, Opt. Express 19, 193-205 (2011)

9. F. Barkusky, A. Bayer, S. Döring, P. Grossmann, K. Mann, Opt. Express 18(5), 4346 (2010)

10. S. Kranzusch, K. Mann, Opt. Commun. 200, 223 (2001)

11. C. Peth, S. Kranzusch, K. Mann, W. Viöl, Rev. Sci. Instrum. 75(10), 3288 (2004)

12. S. Kranzusch, C. Peth, K. Mann, Rev. Sci. Instrum. 74(2), 969 (2003)

13. F. Barkusky, C. Peth, K. Mann, T. Feigl, N. Kaiser, Rev. Sci. Instrum. 76, 105102 (2005)

14. International Organization for Standardization ISO 21254-1:2011 and 21254-2:2011

15. F. Barkusky, Erzeugung intensiver EUV—Strahlung und deren Wechselwirkung mit Materie (Sierke, Berlin, 2010)

16. E. Louis, A.R. Khorsand, R. Sobierajski, E.D. van Hattum, M. Jurek, D. Klinger, J.B. Pelka, L. Juha, J. Chalupsky, J. Cihelka, V. Hajkova, U. Jastrow, S. Toleikis, H. Wabnitz, K.I. Tiedtke, J. Gaudin, E.M. Gullikson, F. Bijkerk, Proc. SPIE 7361, 73610 (2009)

17. V. Nathan, in Laser-Induced Damage in Optical Materials, vol. 1848 (SPIE, Bellingham, 1992), pp. 583-593

18. W.N. Hansen, L. Pearson, G. Hansen, W.J. Anderson, ASTM Spec. Tech. Publ. 726, 247-256 (1980)

19. H.E. Bennett, A.H. Guenther, D. Milam, B.E. Newnam (eds.), Damage in Laser Materials: 1981, Nat. Bur. Stand. (U.S.) Spec. Publ, vol. 638 (1983)

20. A.J. Glass, A.H. Guenther (eds.), Damage in Laser Materials: 1975, Nat. Bur. Stand. (U.S.) Spec. Publ, vol. 435 (1975)

21. H.E. Bennett, A.H. Guenther, D. Milam, B.E. Newnam (eds.), Damage in Laser Materials: 1982, Nat. Bur. Stand. (U.S.) Spec. Publ, vol. 669 (1984) 